Ethiopian Journal of Environmental Studies \& Management 8(2): 171 - 181, 2015.

ISSN:1998-0507

Submitted: November 25, 2014

doi: http://dx.doi.org/10.4314/ejesm.v8i2.7

Accepted: February 12, 2015

\title{
ANALYSIS OF URBAN SLUM DISEASE USING GEO-SPATIAL AND TEMPORAL TECHNIQUES: CASE STUDY FEDERAL CAPITAL CITY OF NIGERIA
}

\author{
*BADARU, Y.M., ${ }^{1}$ OLAYEMI, I.K., ${ }^{2}$ SPENCER, 0. ${ }^{3}$ AND YAKABU, M. ${ }^{4}$ \\ ${ }^{1}$ Applied Remote Sensing Laboratory, Department of Geography, School of Natural and \\ Applied Science Federal University of Technology, Minna, Nigeria \\ ${ }^{2}$ Department of Biological Sciences, School of Natural and Applied Science, Federal \\ University of Technology, Minna \\ ${ }^{3}$ Centre for Satellite Development Technology, National Space Research Development \\ Agency (NASRDA), Abuja, Nigeria \\ ${ }^{4}$ Project Consultant/CEO, Yamiza Nig. Limited, Abuja Investment Neighbourhood Centre, \\ Garki-2, Abuja-Nigeria
}

\begin{abstract}
The study principally concentrates on analyzing urban slums patterns and changes using 2011 NigeriaSat-1 images of the increasing cases of malaria, typhoid, tuberculosis, HIV/AIDS and meningitis in the Federal Capital City (FCC), Abuja. Existing satellite imageries were processed using spatial analysis tools and Statistical Package for Social Science (SPSS) was used to analyze the data collected in the study area as well as determine the magnitude of changes. The results show that malaria and typhoid have been on steady increase with uncontrolled expansion of $34.11 \%$ and $19.50 \%$ respectively as compare to baseline data of 2010-2013 MDGs/FCT health report. On the other hand, tuberculosis 16.94\%, meningitis $15.37 \%$ and HIV/AIDs $14.10 \%$ have also been on increase. The study recommended that urban slum should have a developed policies and strategies to achieve a balanced, coordinated and sustainable health facility. Secondly, to achieve the goal of urban slum without high rate of diseases, governments must undertake vigorous standard guideline for planning, management, infrastructure development, slum upgrading/removal and poverty reduction.
\end{abstract}

Key Words: Mapping, Acceleration, Urban slum, Disease, Remote sensing, Techniques

\section{Introduction}

Urban slums are settlements, neighborhoods, or city regions that cannot provide the basic living conditions necessary for its inhabitants, or slum dwellers, to live in a safe and healthy environment (Badaru et al., 2014). The United Nations Human Settlements Programme (UN-HABITAT, 2003) defines a slum settlement as a household that cannot provide one of the following basic living characteristics: Durable housing of a permanent nature, sufficient living space, and easy access to safe water, Access to adequate sanitation and Security. In the same vein, Dorland's Medical Dictionary (2011) defines disease as a particular abnormal, often construed as a medical 
condition associated with specific symptoms and signs. However, dense and overcrowded slum creates a breeding ground for transmittable diseases, which can lead to the rise of an epidemic. Slum dwellers that do not have access to clean and affordable drinking water are at risk of waterborne and insect-borne diseases (Alexander et al., 2011) and malnutrition, especially amongst children. The same is to be said for slums with no access to adequate sanitation and waste disposal. Moreover, health service does not exist in most of the slums (Riley, 2007). Emergency ambulance service and urgent care is typically unavailable in most of the urban slums (David, 2010). A study shows that more than half of slum dwellers are prone to visit private practitioners or seek self-medication with medicines available in the home (Zaidi, 1999). Diseases recognition and classification (McWhinney, 1987) of an urban slum depends largely on a good knowledge of the area of study; which is usually acquired through thorough fieldworks and ground truthing exercises. The mapping of the occurrences of diseases for a fast growing urban slum like the Federal Capital City of Nigeria is most essential for planning, control and monitoring of health indicators.

Predominantly, slum dwellers usually experience and engender a high rate of multiple diseases transmission (Desai, 2003). However, different diseases reported in urban slums includes: ebola (Fauquet et al., 2005), cholera (Nossiter, 2012), HIV/AIDS (Nyovani et al., 2012), measles (Hambidge et al., 2014), malaria (Bhattacharya et al., 2013), dengue (Alzahrani et al., 2013), typhoid (Corner et al., 2013), drug resistant tuberculosis (World bank, 2013) and other epidemics (Victoriano et al., 2009). Sur et al. (2005) slum prone disease studies focus on addressing high rate of cholera and diarrhea among young children in a typical slum. Besides children in the slum are vulnerable to diseases, as such many scholars also focus on high HIV/AID prevalence in slums among children and women (Ghosh et al., 2009). In some slums, gender inequality increases women's risk of contracting HIV/AIDS. World Health Organization (2004) in their experimental comparisons pointed that diseases can sometimes lead to high mortality in slums. Furthermore, World Health Organization (2004) strongly emphasized that acute poor living conditions also make slum dwellers more vulnerable to certain diseases and, that poor water quality manifest major illnesses including malaria, dengue, lymphatic filariasis, diarrhea and trachoma (Thomas and John, 2010). World Health Organization (2010) documented that appropriate health service does not exist in most of the world's slums. Ahmed (2010) reported that more than half of slum dwellers are prone to visit private practitioners or seek self-medication with medicines available in the home.

Emergency ambulance service and urgent care is typically unavailable in slums (David, 2010). However, as evidenced by Riley et al. (2007) medicinal vendors or chemist practitioner in slums are usually those who are unlicensed or poorly trained and they run clinics and pharmacies mainly for the sake of making more money. Nevertheless, incapacity of slum to handle and organize public health concern can be attributed to potential breeding grounds for diseases vector (Sidi et al., 2005).

\section{Background of the Study Area}

The Federal Capital City, Abuja (FCC) is located in the middle of the country and covers a land area of 250sq.km, at the 2006 population census, the city of Abuja Municipality Area Council had a population of 776,298. The Federal Capital Territory lies within latitudes $9^{\circ} 20^{\prime} \mathrm{N}$ and 
$9^{\circ} 25^{\prime} \mathrm{N}$ of the equator and longitudes $5^{\circ} 45^{\prime}$ $\mathrm{E}$ and $7^{\circ} 39^{\prime} \mathrm{E}$ (Figure 1). The study areas is bordered to the north by Bwari Area Council, to the east by Nasarawa State, to the south west by Kuje Area Council and to the west by Gwagwalada Area Council.
The specific study area includes; Katampe, Jabi, Durumi, Apo, Garki-2, Mabushi, Gishiri and Kpana situated either in city neighborhoods, inner suburbs and city outskirts.

$9^{\circ} 4^{\prime} 0^{\prime \prime} \mathrm{N} 7^{\circ} 29^{\prime} 0^{\prime \prime} \mathrm{E}$

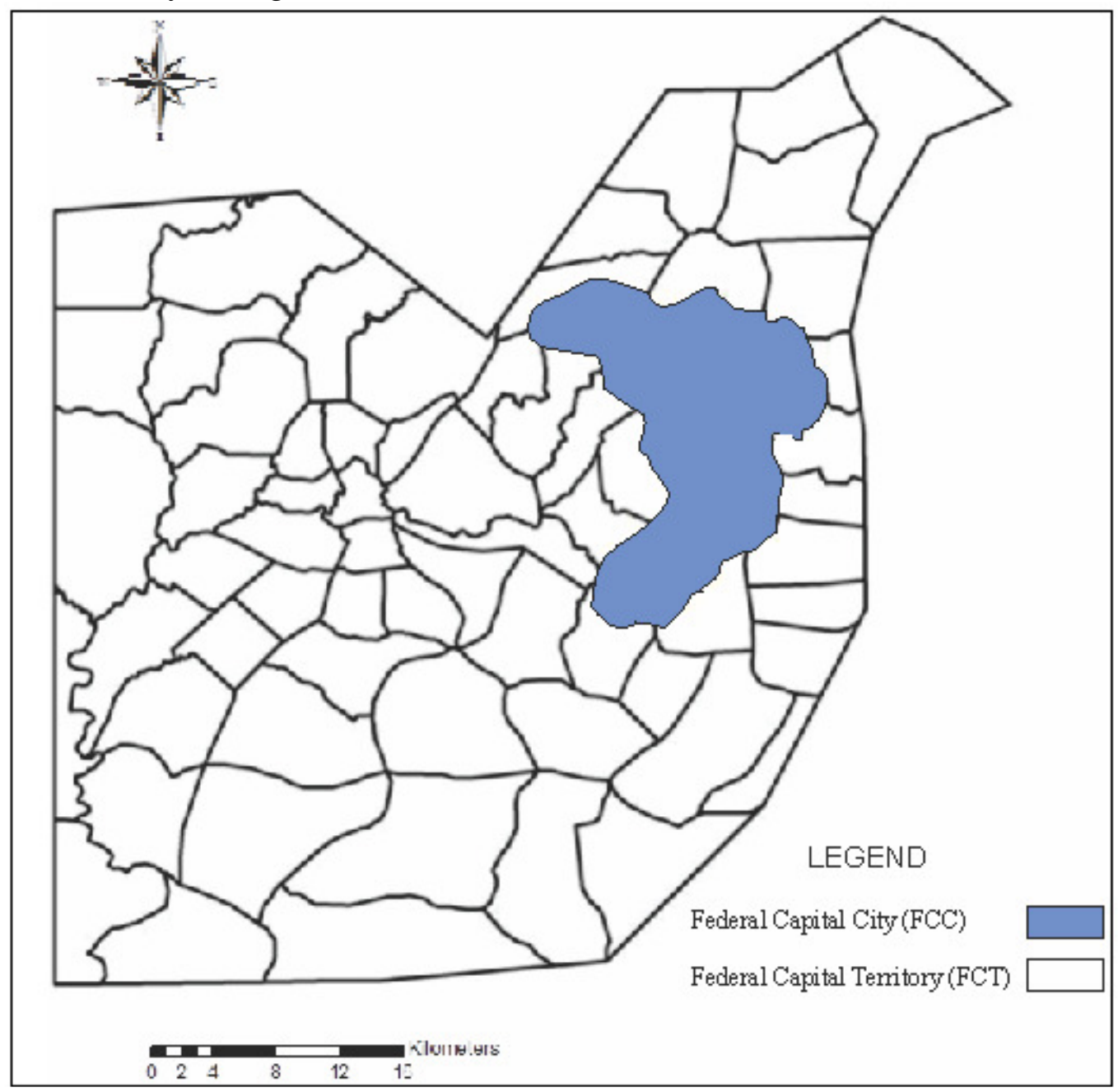

Figure 1: The Federal Capital Territory depicting Federal Capital City Abuja, Nigeria

\section{Statement of Research Problem}

Adopting different methods of image classification algorithms on the same set of disease data could produce appreciable variant results, which is capable of misleading data users and health application administrators. The study attempts to develop a precise procedure algorithms and regression function approach for different diseases which are necessary to provide a standard database for specific applications.

Aim and Objectives

The aim of the study is to analysis the vulnerable state of urban slums to increasing rate of malaria, typhoid, tuberculosis, HIV/AIDs and meningitis in the Federal Capital City, Abuja. The Objectives of the study include: 
- To carry out detailed fieldwork and ground truthing of the site for confirmation and effective validation of the prevailing diseases.

- To map the spatial and temporal distributions of the diseases in the study area using Remote Sensing techniques.

- To carry out a comparative spatial analysis of the diseases slum areas.

\section{Methodology}

The methodology of research is principally by remote sensing data collection, field validation and ground truthing and image processing.

\section{Data Acquisition and Source}

The data collected for the study includes, NigeriaSAT-1 2011 image of the Federal Capital City (FCC), the base map (scale 1:10,000) of the area obtained from the Federal Capital Development Authority, Abuja, and the rectangular grid coordinates (Easting (x) and Northing (y)) of some strategic topographical locations and features in the study area. Vehicles and motor cycles were used to facilitate mobility in and around the eight selected slum area.

\section{Image Classification Procedure}

Having created the signature file, each slum pixel in the study area now have a value in each of the three (3) bands of the NigeriaSAT-1 Imagery, hence the data is ready for supervised classification. Maximum Likelihood (MLC) was carried out on the 2011 NigeriaSAT-1 imagery of the FCC, Abuja, Nigeria using the Image Classification module of ARCMAP-10.1 GIS.

Geo-statistical Approach

According to Badaru et al. (2014), Kriging uses statistical models that allow a variety of output surfaces including predictions, prediction standard errors, probability and quantile, which Kriging is an interpolator that can be exact or smoothed depending on the measurement error model. It is very flexible and allows you to investigate graphs of spatial autoand cross-correlation. In this study, malaria, typhoid, tuberculosis, HIV/AIDs and meningitis of potential importance were statistically matched to urban slum areas, and provided a multivariate description to assess the accuracy of the classifications.

\section{Results and Discussion Malaria}

Figure 3 shows malaria distribution intensity cases in the Federal Capital City's slum areas. The average mean percentage of malaria cases have been estimated out of total malaria cases as follow; Garki-2 8.2\% cases, Kpana $10 \%$ cases, Apo $10.1 \%$ cases, Durumi $12.2 \%$ cases, Jabi $13 \%$ cases, Gishiri $13.1 \%$ cases, Mabushi $16.2 \%$ cases and Katampe $17.2 \%$ cases. The results buttress those of Bhattacharya et al. (2013), who noted that the slum dwellers usually experience a high rate of malaria due to poor sanitary conditions which favour proliferation and rapid development of the vectors and parasites of the disease. 


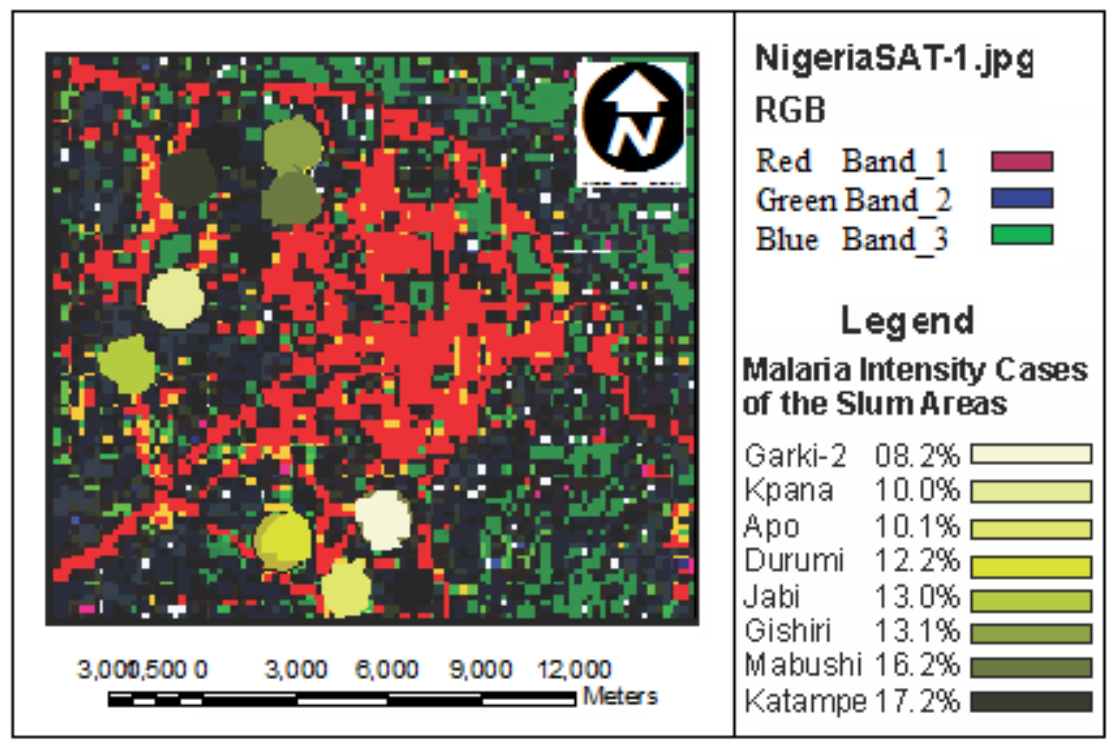

Figure 3: Malaria cases at the urban slums of FCC-Abuja, 2014

\section{HIV/AIDS}

Figure 4 shows HIV/AIDS distribution intensity cases of which average mean have been estimated as follow; Garki-2 6.1\% cases, Kpana 7\% cases, Apo 10.1\% cases, Durumi $11.1 \%$ cases, Jabi $14.6 \%$ cases, Gishiri16\% cases, Mabushi $16.1 \%$ cases and Katampe 19\% cases. The results compare with Piot (2001) on high rate of HIV/AIDS prevalence in slums and concluded that gender inequality and inadequate accommodation increases women's risk of HIV/AIDS.

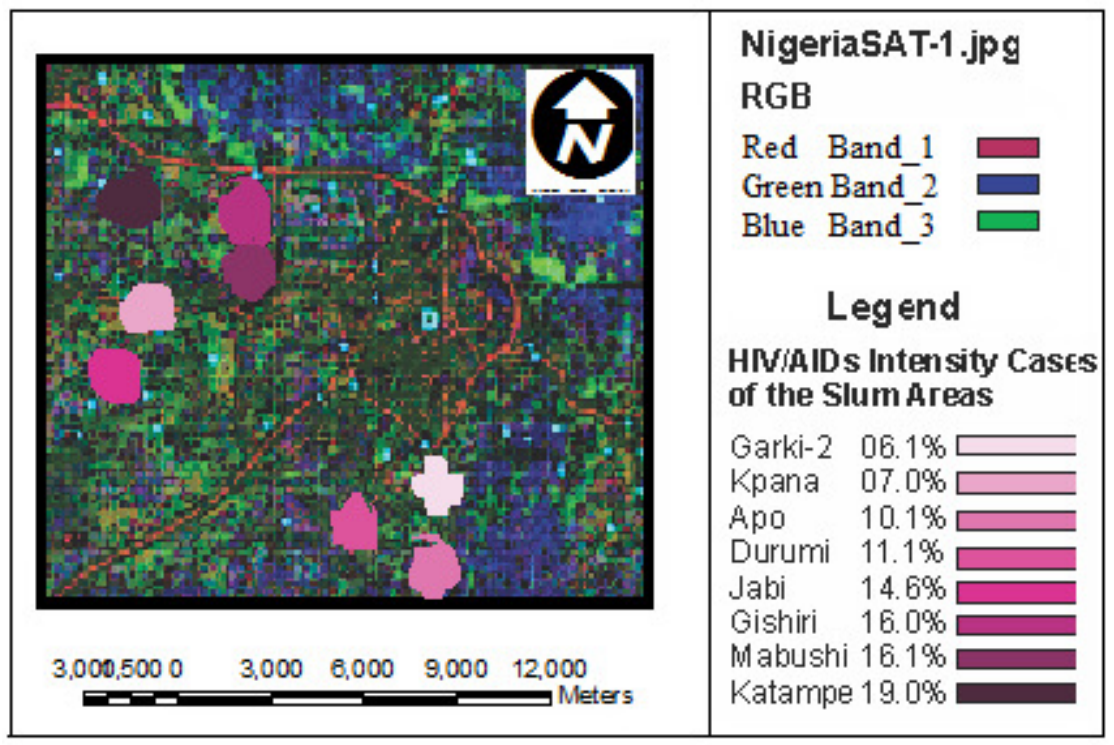

Figure 4:HIV/AIDs cases at the urban slums of FCC-Abuja, 2014

\section{Tuberculosis}

Figure 5 shows drug resistant tuberculosis distribution intensity cases in the study area; Kpana 10.1\% cases, Garki-2 10.3\% cases, Durumi 10.4\% cases, Katampe 11\% cases, Apo $12.1 \%$ cases, Gishiri $13 \%$ cases, Jabi $16.1 \%$ cases and Mabushi $17 \% \%$ cases. The results 
buttress those of Kyobutungi (2008), according to his study in Nairobi's slums that HIV/AIDS and tuberculosis attributed to mortality burden among slum dwellers.

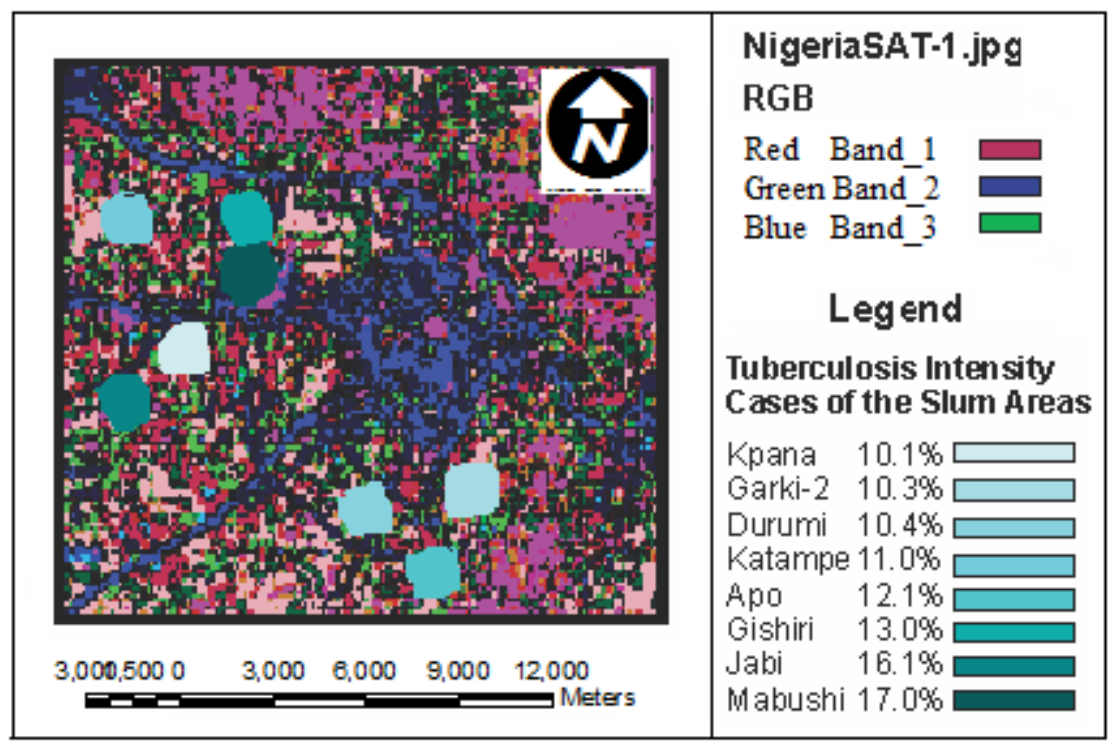

Figure 5: Tuberculosis cases at the urban slums of FCC-Abuja, 2014

\section{Typhoid}

Figure 6 shows typhoid distribution intensity cases of which the average mean have been estimated as follow; Apo 10.2\% cases, Garki-2 11\% cases, Kpana 11.1\% cases, Durumi $12.1 \%$ cases, Jabi $13.1 \%$ cases, Gishiri $13.2 \%$ cases, Katampe $14.1 \%$ cases and Mabushi $15.2 \%$ cases. The results buttress those of Corner et al. (2013), who states that poor living conditions and poor water quality also make slum dwellers more vulnerable to certain diseases, including malaria, typhoid, diarrhea and trachoma.

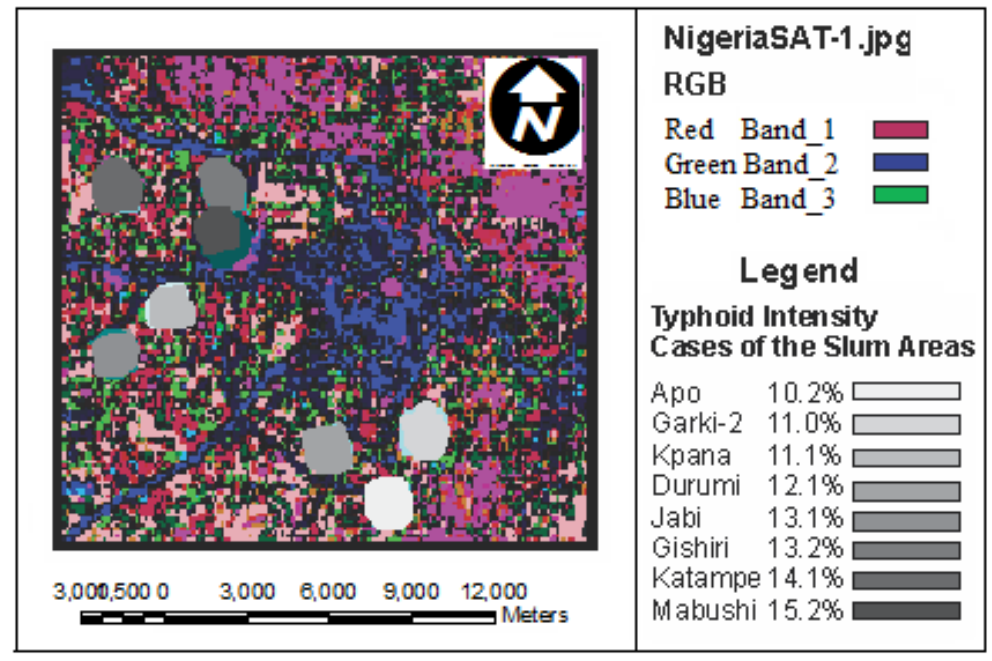

Figure 6: Typhoid cases at the urban slums of FCC-Abuja, 2014

\section{Meningitis}

Figure 7 shows meningitis intensity cases in the FCC's urban slum. The average mean are estimated as follow; Garki-2 10\% cases, Kpana 11.1\% cases, Durumi 12\% cases, Jabi 13\% cases, Gjshiri $13.1 \%$ cases, Apo $13.3 \%$ cases, Katampe $13.5 \%$ cases and Mabushi $14 \%$ cases. 
This results buttress those of Ko AI Reis et al. (1999) who explains that in Brazil a large proportion of the residents of this shantytown suffered from a variety of chronic illnesses, both infectious and non-infectious. This includes meningitis, hypertension, diabetes, asthma, intentional and unintentional injuries, mental illnesses, complications of drug and alcohol use, sexually-transmitted infections, and reproductive health problems.

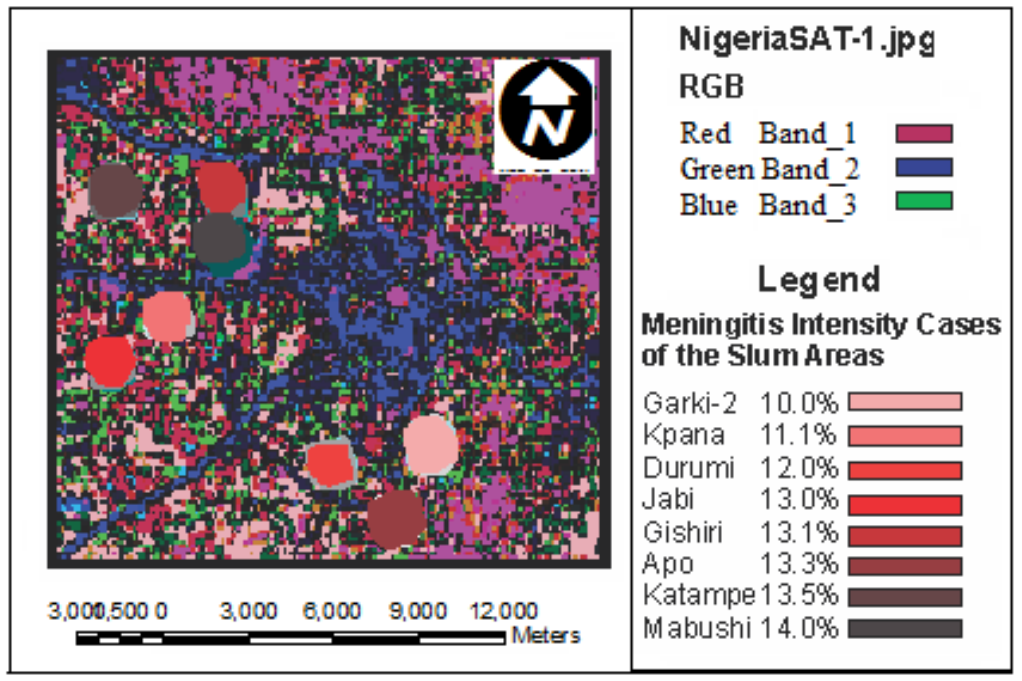

Figure 7: Meningitis cases at the urban slums of FCC-Abuja, 2014

\section{Diseases-slum Level}

Figure 8 shows the graphic representation of disease types, location and distribution frequency of the study area. The Figure illustrates that 69\% (high) and 48\% (low) of malaria cases is recorded for Katampe and Garki-2 respectively, typhoid fever records $42 \%$ (high) and 20\% (low) for Mabushi and Apo respectively, others are tuberculosis that record $40 \%$ (high) and $15 \%$ (low) for Mabushi and Kpana respectively, HIV/AIDs also records $34 \%$ (high) and $14 \%$ (low) for Katampe and Garki-2 respectively, while meningitis records $38 \%$ (high) and $28 \%$ (low) for Katampe and Garki-2 respectively. 


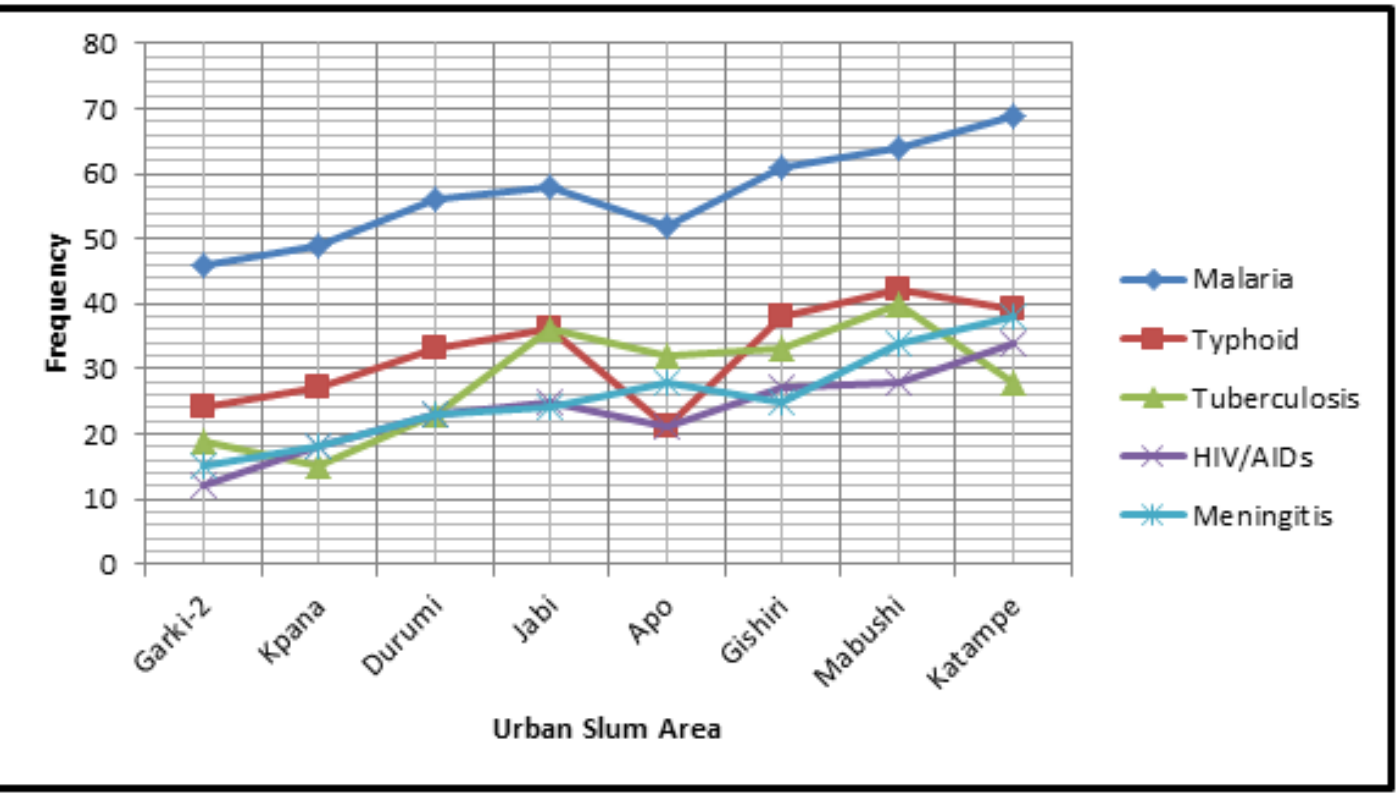

Figure 8: The distribution of diseases at the slum level of FCC-Abuja, 2014

\section{Regression Analysis}

Figures 9 show relationship that exists between the observed disease types and the slum areas. The Figure 9 illustrates coefficients of determination $\mathrm{R}^{2}$ estimated by these regression analysis that shows malaria, typhoid, tuberculosis, HIV/AIDs and meningitis indicating this values 0.85 (85\%), $0.47(47 \%), 0.91$ (91\%), $0.85(85 \%)$ and $0.52(52 \%)$ respectively. The Figure 9further indicates that malaria, typhoid, tuberculosis, HIV/AIDs and meningitis positively correlate with the state of slum in the study area. The test of goodness of fit on the regression line conducted shows a high strength of $72 \%$ in the relationship between the diseases and slum areas.

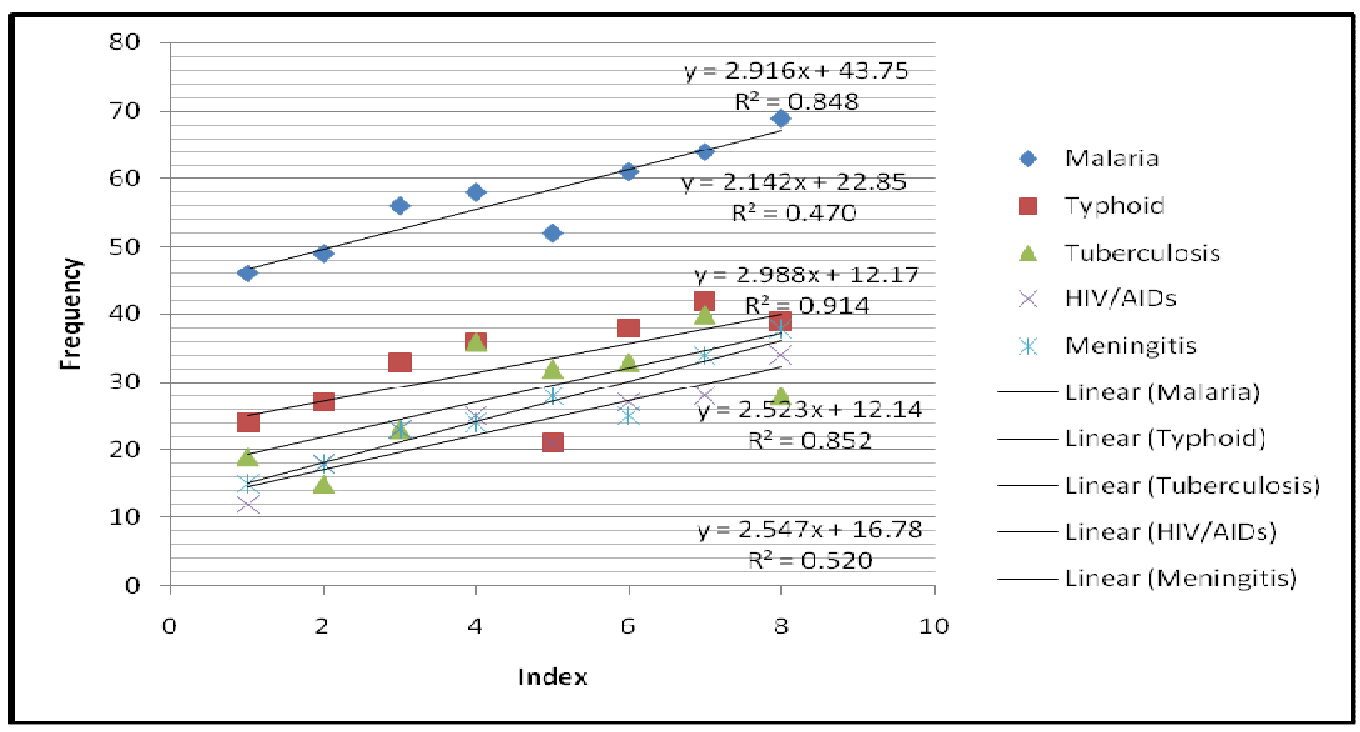

Figure 9: The regression function of diseases at the slum area of FCC, 2014 
A close examination of the classified maps (Figures 3-7) of the study area, indicate malaria (Figure 3) as the most vulnerable and shows endemic quality level of the area ahead of typhoid, tuberculosis, HIV/AIDS and meningitis. The detail classification of the calculated urban slum and diseases value shows that malaria $34.11 \%$ and typhoid $19.50 \%$ are considered a major public health concern. In the same vein tuberculosis $16.94 \%$, meningitis $15.37 \%$ and HIV/AIDS $14.10 \%$ also engender a high rate of transmission in the study area. This result shows malaria as the most pronounced disease, and has adequate and available potential breeding grounds in the study areas. Besides urban slum's vulnerability to HIV/AIDS prevalence in slums, HIV/AIDS have the lowest cases among the dwellers. The result from regression analysis (Figure 8 and 9) varied greatly from each other of which malaria 0.85 (85\%), typhoid $0.47 \quad(47 \%)$, tuberculosis 0.91 (91\%), HIV/AIDS 0.85 $(85 \%)$ and meningitis $0.52(52 \%)$, meaning that some diseases are more vulnerable to slum than other. This mapping and classification algorithm adopted for slumdisease verification produced the best result in this research.

\section{Conclusion}

Abuja urban slum is a ward located in the suburbs of Federal Capital City. Unlike many urban slums, majority of residents are typically employed and work for extremely small wages in the transport (okada), shopping mall (seller), restaurant (waiter) and offices (cleaner) that slum is known for. However, despite a surprising rise of diseases, residents have limited access to working toilets and therefore they resort to relieving themselves in the nearby bush or open-spaces. Unfortunately, several wells are situated in the open-spaces, also serves as a source of drinking water, which is a scarce commodity in the study area. Thousands of residents fall ill with new cases of malaria, dysentery, measles, dengue and tuberculosis each day due to the consumption of polluted local water sources. In addition, the mapping of slum shows that the study areas are more diseases prone slums because of their location to impacts of mosquitoes breeding sites, solid and liquid waste scattered on the environment, poor living conditions, poor ventilation, most lack reliable sanitation services, supply of clean water, reliable electricity, timely healthcare provider and other medical basic services. The mapping of the vulnerability of urban slum to diseases in the study shows that more than $85 \%$ of slum dwellers are prone to malaria, typhoid, tuberculosis, HIV/AIDS and meningitis, sometimes seek self-medication available in the home. In addition, mapping urban slums are considered a major achievement toward assessing health for all before 2015 postulated by MDGs goal and public health concern. Slum prone disease is an enemy that must be feared, fought, battled, and routed if the urban are to exist. Insufficient space for ventilation, high population densities, poor living conditions, insufficient health-related data, inadequate health service and poor quality water manifest a cause of many illnesses including malaria, typhoid, tuberculosis, HIV/AIDS and meningitis high rate of transmission in the slum area of the Federal Capital City, Abuja.

\section{Acknowledgement}

My special thanks and appreciation goes to National Space Research Development Agency, Abuja and Remote sensing laboratory, department of 
Geography, Federal University of Technology, Minna, Nigeria for making the data used in this study available. I also appreciate Chiefs of all the study areas where the preliminary data collection and enhancement was carried out.

\section{References}

Alexander, V.G. (2011). Impact of population and latrines on fecal contamination of ponds in rural Bangladesh. Science of the Total Environment, 9(17): 3174-3182.

Alzahrani, A.G., AlMazroa, M.A., Alrabeah, A.M., Ibrahim, A.M., Mokdad, A.H. and Memish, Z.A. (2013).Geographical distribution and spatio-temporal patterns of dengue cases in Jeddah Governorate from 2006-2008.TransnationalRoyal

Society Tropical Medicine Hygiene. 107(1): 23-9.

Ahmed, M.M. (2010). Clinical profile of dengue fever infection in King Abdul Aziz University Hospital Saudi Arabia. Journal of Infectious Dev. Ctries. 4(8): 503-510.

Badaru, Y.U., Abubakar, A.S., Spencer, O., Adejoke, A.O. and Salihu, S.O. (2014). Assessment Of Housing Conditions For A Developing Urban Slum Using Geospatial Analysis: A Case Study Of Durumi, Garki-2, Gishiri And Jabi Of The City Of Abuja, Federal Capital Territory Of Nigeria. IISTE-Journal of Environment and Earth Science, 4(20): 1-15

Bhattacharya, S. K., Sur, D., Dutta, S., Kanungo, S., Ochiai, R. L., Kim, D. R. and Deen, J. (2013). Vivax malaria and bacteraemia: a prospective study in Kolkata, India. Malaria journal, 12(1), 176-178
Corner, R.J., Dewan, A.M. and Hashizume, M. (2013). Modelling typhoid risk in Dhaka Metropolitan Area of Bangladesh: the role of socioeconomic and environmental factors International Journal of Health Geographics, 13(21): 32-45.

David, M. (2010). Adult mortality in slums of Karachi, Pakistan David Marsh, JPMA

Desai, V.K. (2003). Study of measles incidence and vaccination coverage in slums of Surat city. Indian Journal of Community Medicine: 28 (1).

Dorland's Medical Dictionary (2011). Dorland's Illustrated Medical Dictionary, Deluxe, 32nd Edition

Fauquet, C.M. and Stanley, J. (2005). Revising the way we conceive and name viruses below the species level. A review of geminivirus taxonomy calls for new standardized isolate descriptors. Arch Virol in press.

Ghosh, A.,Vidale, J.E., Sweet, J.R., Creager, K.C. and Wech, A.G. (2009), Tremor patches in Cascadia revealed by seismic array analysis, Geophysical Resource Letter, 36, L17316, doi:10.1029/2009GL039080.

Hambidge, S.J., Newcomer, S.R., Narwaney, K.J., Glanz, J.M., Daley, M.F., Xu, S., Shoup, J.A., RowhaniRahbar, A., Klein, N.P., Lee, G.M., Nelson, J.C., Lugg, M., Naleway, A.L., Nordin, J.D., Weintraub, E. and DeStefano, F. (2014). Timely versus delayed early childhood vaccination and seizures. 133(6):e1492-9. doi: 10.1542/peds.2013-3429.

Ko A.I., Reis, M.G., Dourado, C.M.R., Johnson, W.D., and Riley, L.W., (1999). Salvador Leptospirosis Study Group: Urban epidemic of severe 
leptospirosis in Brazil.Lancet, 354: 820-825.

Kyobutungi, C. (2008). The burden of disease profile of residents of Nairobi's slums: Results from a Demographic Surveillance System. Population Health Metrics 6(1).

McWhinney, I.R. (1987). Health and disease: problems of definition. $\begin{array}{llll}\text { CMAJ } & 136 & \text { (8): } & 815 .\end{array}$ PMC 1492121.PMID 3567791.

Nossiter, A. (2012). Cholera epidemic envelops coastal slums in West Africa. The New York Times. Retrieved from: http://www.nytimes.com/2012/08/23/ world/africa/cholera-epidemicenvelops-coastal-slums-in-westafrica.html?_r=1\&hp

Nyovani, J.M., Ziraba, A.K., Inungu, J.K, Samoel, A., Ezeh, A.Z., Eliya M., Kebaso, J., Okoth, V. and Mwau, M. (2012).Are slum dwellers at heightened risk of HIV infection than other urban residents? Evidence from population-based HIV prevalence surveys in Kenya.Health and Place, 18 , (5), 1144-1152. (doi:10.1016/j.healthplace.2012.04.00 $3)$.

Piot, P. (2001). A gendered epidemic: Women and the risks and burdens of HIV. Journal of the American Medical Womens Association 56: 9091.
Riley, L.W. (2007). Slum health: diseases of neglected populations. $B M C$ international health and human rights 7(1).

Sidi, G., Davidovitch, N., Balicer, R.D., Anis, E., Grotto, I. and Schwartz, E. (2005). Tick borne relapsing fever in Israel. Emerging Infectious Diseses 11: 1784-6.

Thomas, Q. and John, B. (2010), Global infectious diseases and urbanization, Urban Health: Global Perspectives, $18,105$.

United Nations Human Settlements Programme (2003). The Challenge of Slums: Global Report on Human Settlements

Victoriano, A.F.B., Smythe, L.D., GlorianiBarzaga, N., Cavinta, L.L., Kasai, T., Limpakarnjanarat, K., Ong, B.L., Gongal, G., Hall, J., Coulombe, C.A., Yanagihara, Y., Yoshida, S. and Adler, B. (2009). Leptospirosis in the Asia Pacific region.BMC Infectious Disease doi: 10.1186/1471-2334-9147.

World Health Organization (2004). Water, Sanitation and Hygiene Links to Health: Facts and Figures.

Zaidi, S.S.A. (1999). Environmental impact on Health, An overview. Azad Academy Journal 15(11): 29- 34. 